\title{
EXPLORING THE CYC CIS-TEM: A LITERATURE REVIEW OF QUEER AND TRANS TOPICS IN CHILD AND YOUTH CARE
}

\section{Mattie Walker}

\begin{abstract}
Although Child and Youth Care (CYC) sees itself as a field that embraces diversity and complexity, there is a notable lack of discussion of sexual and gender diversity: queer and trans topics are rarely taken up across CYC research, practice, and pedagogy. Through a systematic literature review of articles published between 2010 and early 2020 in six journals with a focus on CYC practice, research, and theory, this article assesses how queer, trans, Two-Spirit, and nonbinary identities and topics are being discussed in the current CYC literature and reveals a conspicuous absence of publication on these topics. In a 10year period, across six CYC publications comprising over 4000 published articles, only 36 articles focused on queer and LGBT issues (by covering both sexual and gender diversity) and, of those, only eight articles specifically focused on gender diversity or trans topics. No articles were found within any of the reviewed publications that specifically focused on Two-Spirit identities or topics and only one article mentioned nonbinary identities. Through exploring how and where queer and trans, Two-Spirit, and nonbinary identities and topics are being discussed, this review asks how we as a CYC field might begin to make space for these topics within our field and practice, in order to work towards social change that shifts our field and challenges the cis-heteronormative CYC system.
\end{abstract}

Keywords: queer; LGBTQ; gender; transgender; trans; Two-Spirit; nonbinary; gender diversity; child and youth care; cisnormativity

Mattie Walker MA is a graduate of the School of Child and Youth Care and a current $\mathrm{PhD}$ student in the Social Dimensions of Health Program at the University of Victoria, 3800 Finnerty Road, Victoria, BC V8W 2Y2. Email: mattiew@uvic.ca 
White (2015) described child and youth care (CYC) as a field that recognizes itself as "a site of contested meanings, where ongoing debates about identities, roles, boundaries of practice, and professional status continue to animate the field" (p. 499). CYC is often articulated as a practice and field that is about possibilities, creating spaces, and finding opportunities (Vachon, 2020), challenging dualisms and normative practices (Skott-Myhre, 2012), and emphasizing the importance and value of difference (de Finney et al., 2012). Nevertheless, despite this emphasis on CYC as a field that embraces diversity and complexity, there is a noticeable gap in how sexual and gender diversity are being discussed in the field and how queer ${ }^{1}$ and trans topics are being taken up across research, practice, and pedagogy in CYC. "Care permeates queerness" (Vachon, 2020 , p. 63), yet where is the queerness of CYC?

This literature review was born out of a question that I have been asking myself throughout my experiences with CYC pedagogy, both during my education in CYC in undergraduate and graduate programs, and in my work as a sessional instructor with the School of Child and Youth Care at the University of Victoria. The literature explored in course content and classroom discussions gave little attention to queer and trans topics and identities despite an ongoing wider conversation about the diversity of CYC practice and pedagogy. I found myself wondering how and where queer and trans topics were being discussed in our field when my own experience in this CYC context had left me at a loss. In my own educational experiences, queer topics seemed limited to short textbook passages offering brief overviews of gay and lesbian identity in adolescent development, or the section called "Lesbian and Gay Therapy" in a chapter on feminist therapy in Jones-Smith (2016). These topics are often offered as a subtopic within a larger theme of feminism or adolescent development. I remember two particular conversations, one when I was a teaching assistant speaking with the instructor of a class on change theory, and the other when I was the instructor and my teaching assistant was commenting on the lack of content; in each case we each shook our heads at the limited representation and questionable presentation of the information available in the course textbook but wondered whether it is better to include a cursory nod to queer content, or no queer content at all. While some queer content and brief acknowledgement of gay and lesbian experiences did find themselves into my CYC learning and education, I noticed an even larger gap regarding attention to gender diversity, and specifically trans, Two-Spirit, and nonbinary (T2SNB) identities and experiences. I can think of only one class in my undergraduate and graduate course experiences where we specifically discussed gender identity and transgender experiences and this was limited to one unit in a much larger course.

\footnotetext{
${ }^{1}$ The term queer has been taken up as an umbrella term for people who do not identify as strictly heterosexual (Everett et al., 2013). Although this term is widely used to broadly refer to a multitude of identities, including gay, lesbian, bisexual, transgender, and queer-identified, this term is also considered problematic for many reasons (Anzaldúa, 1991; Fassinger \& Arsenau, 2007, in Everett et al., 2013). The term is used within this review with this tension in mind. The term trans is used alongside queer to indicate experiences with gender that are not cisgender but, as not all individuals who identify as trans identify as queer, these terms are used separately with the awareness that there is overlap as well as distinction between them.
} 
International Journal of Child, Youth and Family Studies (2021) 12(3/4): 23-54

These experiences left me wondering how CYC practitioners (CYCPs) are being educated about queer and T2SNB topics, particularly in relation to practice concerns, contexts, and challenges. It also raised the question of how and where queer and T2SNB CYC students are seeing themselves and their experiences represented and discussed in relation to their future practice when so much of our CYC learning appears to be from a cis-heteronormative perspective.

Shipherd and Sloan (2019) noted that, while an interdisciplinary approach to the health and well-being of queer and T2SNB people is indicated within the literature, consistent and reliable research on how best to support the mental health needs of these communities has only just begun. CYCPs are well positioned to provide much needed support and care to queer and T2SNB young people (Taylor, 2020); however, the lack of available research about these URHspecific populations makes it difficult to know how to proceed (Lev, 2004; Mizock \& Lewis, 2008). As Craig and Austin (2017) cautioned, "A clear understanding of gender identity development and the range of gender experiences among children and adolescents, as well as the associated terminology, is a prerequisite for all discussions of gender identity-specific healthcare needs and potential interventions" ( $\mathrm{p} .57$ ), but when and where is this education occurring to properly prepare CYCPs to practise competently with queer and T2SNB individuals and communities?

This literature review seeks to explore how these topics are being discussed in the CYC literature in order to identify themes and areas of focus, and to make visible the gaps that are present in this field. In starting this process, I was particularly interested in locating where and how T2SNB identities and topics are being specifically discussed in CYC, in addition to queer content more broadly. Gender diversity is often discussed as part of, or related to, the larger lesbian, gay, bisexual, transgender, and queer (LGBTQ) communities; however, a common sentiment within discussions of LGBTQ topics and identities is that the $\mathrm{T}$ is often silent (Jenkins, 2015). While my question about queer and trans topics in CYC is related and intertwined with LGBQ identities and topics and queerness itself, my focus and emphasis are on T2SNB identities and topics, to actively work against this silencing that so often occurs.

In order achieve these ends, this literature review explored articles published in six academic and practice publications that focus on CYC research, practice, and theory. The following sections describe the method used for the literature search and review and the results of the keyword search, as well as the three primary themes identified.

\section{Method}

Starting with the question, "How and where are queer and T2SNB identities and theories being discussed in CYC literature and research?", I identified six key publications: Children and Youth Services Review; The International Journal of Child, Youth and Family Studies; Child and Youth Services; CYC-Online; Child and Youth Care Forum; and Relational Child and Youth Care Practice. These publications were chosen as I have seen them utilized and referenced often in CYC classrooms, the $\mathrm{CYC}$ curriculum, and research in my experience as both a student and instructor 
within the School of Child and Youth Care at the University of Victoria. Some of the publications are peer reviewed and academic (Children and Youth Services Review; The International Journal of Child, Youth and Family Studies; Child and Youth Services; Child and Youth Care Forum) while two (CYC-Online, Relational Child and Youth Care Practice) are publications that concern practice and do not utilize a peer-review process; however, Relational Child and Youth Care Practice does provide peer review at the request of the author.

As a next step, I searched within each journal using the following individual search terms: gender, gender nonconforming, gender variant, transgender, LGBTQ, queer, Two-Spirit, and nonbinary. Searches were conducted directly within the journal publication using keywordanywhere searches spanning 2010 to early 2020.

\section{Search Terms}

Search terms were chosen that would identify articles focusing on the topic in question. As the goal of this literature review was to explore how queer topics and T2SNB identities and issues were being discussed within CYC literature, each of these terms was used as a search term. I started with the broad search term of gender and then began narrower searches that used specific identity descriptors. Although not specific identity terms, gender nonconforming and gender variant were utilized to capture broad descriptors that are sometimes used to describe a range of diverse gender identities outside of cisgender identities. Specific identity terms, such as transgender, Two-Spirit, and nonbinary, were searched individually. For terms that had slight variations (nonbinary/nonbinary, nonconforming/non-conforming, two-spirit/Two-Spirit/Two Spirit, variant/variance, transgender/trans), all variations were used and included in the search results.

I searched for the term $L G B T Q$, as it is the most commonly used version of the acronym identifying lesbian, gay, bisexual, transgender, and queer identities. Many different variations of this acronym are used in different community contexts; however, most start with "LGBTQ" so variations with additional characters were also found by this search. For example: "LGBTQ2+" (addition of " 2 " for Two-Spirit and " + " to indicate that additional identities are included but not represented by a specific letter) or "LGBTQIA" (addition of "I" for intersex and "A" for asexual).

Articles were considered generally relevant (a) if they discussed or included any of queer, LGBTQ, and T2SNB topics or issues; (b) if they utilized or drew on queer or trans theories; (c) if the primary topic was an example of gender being discussed in CYC despite not referencing trans topics specifically; or (d) if the article mentioned that the primary topic was relevant and important to consider in relation to queer and T2SNB communities. Additionally, articles that focused on queer and T2SNB topics were separately categorized if the primary or a main focus was specifically on one or more of these topics. Also included were articles that made mention of queer, LGBTQ, or transgender identities or topics, (e.g., including transgender youth as a population of focus for a research project on youth homelessness) or mentioned them in their discussion (e.g., taking into consideration queer youth issues; or including queer and trans identities in a larger discussion about diversity or marginalized communities). 


\section{Overview of the Findings}

The six publications examined published over 4000 articles from 2010 to 2020. Out of these, just 58 relevant articles were located, of which only 36 focused on sexual and gender diversity issues and topics, and only eight took gender diversity or transgender identities or issues as a main topic. These search results are presented in Table 1, which outlines for each publication the total number of articles, spanning 2010 to early 2020, located with a keyword-anywhere search on the identified terms.

Table 1. Journal Keyword Search Results Depicting Total Number of Articles Located with Identified Search Terms by Publication Spanning 2010 to 2020

\begin{tabular}{lrrrrrrrrrrc}
\hline & \multicolumn{10}{c}{ Search categories (see notes) } \\
\cline { 2 - 10 } Journal & \multicolumn{1}{c}{$\mathrm{G}$} & $\mathrm{GN}^{\mathrm{a}}$ & $\mathrm{GV}^{\mathrm{b}}$ & \multicolumn{1}{c}{$\mathrm{T}$} & $\mathrm{L}$ & $\mathrm{Q}$ & $2^{\mathrm{c}}$ & $\mathrm{NB}^{\mathrm{d}}$ & $\mathrm{IR}$ & $\begin{array}{c}\text { Total } \\
\text { (SG div) }\end{array}$ & $\begin{array}{c}\text { Total } \\
\text { (Gender) }\end{array}$ \\
\hline CYSR & 2529 & 5 & 5 & 101 & 65 & 46 & 7 & 14 & 24 & 18 & 2 \\
IJCYFS & 76 & 1 & 12 & 7 & 3 & 14 & 2 & 0 & 20 & 8 & 4 \\
CYS & 109 & 3 & 1 & 14 & 7 & 20 & 2 & 2 & 8 & 4 & 1 \\
CYC-Net & 6 & 0 & 0 & 2 & 1 & 0 & 0 & 0 & 3 & 3 & 1 \\
RCYCP & 3 & 0 & 0 & 0 & 1 & 2 & 0 & 0 & 3 & 2 & 0 \\
CYCF & 317 & 0 & 0 & 1 & 1 & 2 & 0 & 1 & 0 & 0 & 0 \\
Total & 3040 & 9 & 18 & 125 & 78 & 84 & 11 & 17 & 58 & 36 & 8 \\
\hline
\end{tabular}

Notes. Results indicate search results from keyword anywhere searches using the search term identified. For terms where slight variations exist, results include search results for all variations.

Search category codes: $G=$ Gender, $G N=$ Gender nonconforming, $G V=$ Gender variant, $T=$ Transgender), $\mathrm{L}=$ LGBTQ, Q = Queer, 2S = Two-Spirit, NB = Non-binary, IR = Included as relevant,

Total SG div = Total unique articles focusing on both sexual and gender diversity - i.e., queer or LGBTQ topics, Total Gender $=$ Total unique articles focusing on gender diversity, trans, Two-Spirit, nonbinary identities and topics . Journal abbreviations: CYSR = Children and Youth Services Review; IJCYFS = International Journal of Child, Youth and Family Studies; CYS = Child and Youth Services; CYC-Net = CYC-Net (CYC Online); RCYCP = Relational Child and Youth Care Practice; CYCF $=$ Child and Youth Care Forum.

${ }^{\mathrm{a}}$ searched as non-conforming and nonconforming; ${ }^{\mathrm{b}}$ searched as variant and variance; ${ }^{\mathrm{c}}$ searched as two spirit and two-spirit; ${ }^{\mathrm{d}}$ searched as nonbinary and non-binary.

It is notable that out of the 58 articles that were located, just eight focused on gender diversity or trans identities and issues. Each of the eight used transgender as an umbrella term. Within the reviewed publications, no articles were located that specifically focused on Two-Spirit or nonbinary identities, topics, or issues, except for Lebuis (2018), which explicitly mentioned nonbinary identities in referring to both sexual and gender identity. While both Two-Spirit and nonbinary are often encompassed under the "transgender umbrella", they are distinct identity terms that connote distinct experiences of gender. 
International Journal of Child, Youth and Family Studies (2021) 12(3/4): 23-54

It is also crucial to note that Two-Spirit identities are particular to Indigenous cultures and encompass a range of identities, related to both gender and sexual identity that complicate distinctions between gender, sex, and sexuality (Hunt, 2016). This term and associated identities are culturally bound and grounded in traditional knowledges, cultures, and languages (Hunt, 2016). To see that not one article within the CYC literature in the last 10 years has specifically spoken in support of Two-Spirit young people highlights the fact that CYC continually needs to be improving itself as a field by decolonizing our practices and centring and holding space for Indigenous ways of knowing, being, and doing this work. Due to the lack of specific attention to Two-Spirit identities, the discussion of Two-Spirit individuals and identities will be glaringly absent. Similarly, as nonbinary identities were mentioned only in Lebuis (2018), they also will not be featured in this review.

The following sections provide an overview of the terminology found in the literature search and the review, followed by a brief summary of the findings within each journal.

\section{Terminology Within Articles Reviewed}

In the literature search and in this review, the terms queer and trans are utilized not only as identity terms and categories but also to engage with queer and trans theories and politics. As Lee (2019) articulated, "Critical queer and trans theories unpack how social institutions, processes, and practices reproduce heterosexuality (heteronormativity) and the gender binary and the erasure of trans people (cisnormativity), thus operating to reinforce dominant social norms (Cohen, 1997; Stryker, 2008)" (p. 73). These terms are taken up in this review in order to capture works that speak to queer and trans identities as well as to the critical theories and politics that challenge the dominant social norms within our social and professional contexts in CYC.

Defining terminology, particularly the terms trans and transgender, was a common practice in many of the articles I reviewed. Arguably, the fact that authors writing on these topics must continue to define what trans means for the reader speaks to the lack of general knowledge, familiarity, and understanding of these identities within this field. While there are many identities and terms we no longer must define each time we write about these topics, gender and sexual diversity continues to be a topic in which lack of familiarity is not only presumed, it is expected. When discussing gender identities, the majority of the 58 relevant articles used the term trans or transgender. Many articles also used variations of gender diversity, gender diverse, and gender expansive as broad umbrella terms. Therefore, for the discussion section of this review, the term trans will be utilized as an umbrella term capturing a variety of gender identities and experiences.

In my previous research outside this literature review, and in personal and professional experiences, I have found that the acronym T2SNB, for "trans, Two-Spirit, and nonbinary", is often used as an umbrella term that encompasses a diverse array of identities, including genderqueer, gender fluid, gender flux, and others; this terminology continues to evolve as individuals and communities create and utilize language in unique ways to describe and discuss their identities (Everett et al., 2013; Walker, 2017). However, neither this acronym nor a discussion 
of the underlying complexities and distinctions was present in any of the reviewed literature. Although T2SNB people are often discussed as if they are a single population within the broader category of LGBTQ, or even within the trans umbrella, the experiences of T2SNB populations cannot be collapsed or seen as homogeneous (Alessi \& Martin, 2017). Each of these populations faces unique and diverse experiences of oppression, minoritization, erasure, advocacy, visibility, and subjection to structural violence, along with other complex intersections of identity and subjectivities in relation to dominant and hegemonic power and systems of political, cultural, and social power (Alessi \& Martin, 2017; Shelley, 2008; Spade, 2015). As Mayo (2017) stated, "These complexities are more than anecdotal; they are constitutive" (p. 536), so holding space for complexity in service provision becomes an essential part of delivering accessible and respectful care. Nevertheless, due to the lack of specific identification and consistent terminology usage across the literature reviewed, the current paper utilizes the broad (and notably limited) umbrella term "transgender" (or "trans"), which has implications not only for this discussion but also for the relevance of the currently available literature to Two-Spirit and nonbinary communities, and to those who define themselves in ways that are not specifically trans but also are not cisgender. Utilizing the language discussed above, the following sections provide a brief summary of the findings within each journal. Journals are listed in order from most results to least.

\section{Children and Youth Services Review}

Children and Youth Services Review contained 24 relevant articles, including 18 that focused on LGBTQ topics, and two that focused on trans topics (Goldberg et al., 2020; Shelton, 2015). These articles concerned themselves with a range of topics:

- youth homelessness (Begun et al., 2019; Coolhart \& Brown, 2017; Côté \& Blais, 2019; Maccio \& Ferguson, 2016; Mountz \& Capous-Desyllas, 2020; Prock \& Kennedy, 2017; Rew et al., 2019; Shelton, 2015);

- sexual exploitation (Hounmen \& O’Grady, 2019);

- the child welfare system and foster care experiences (Goldberg et al., 2019, 2020; Scannapieco et al., 2018; Wilson \& Kastanis, 2015);

- bullying and harassment (Barth \& Olsen, 2020; Wernick \& Kulick, 2013; Wernick et al., 2013);

- mental health support interventions, resources, and outcomes (Craig \& Austin, 2016; Chiang et al., 2018; Richards-Schuster et al., 2013; Scannapieco et al., 2018; Wagaman et al., 2020; Wells et al., 2013); and

- school safety (Atteberry et al., 2019; Seelman et al., 2015). 
International Journal of Child, Youth and Family Studies (2021) 12(3/4): 23-54

Additional articles contained the search term transgender, but because the topics covered in these articles were not specific to transgender experience, or because the term was only mentioned once during the article, these publications were not considered relevant and were not included in the results of this literature review. In these articles, the search terms of interest were used:

- as notes regarding demographic information with no specific discussion (e.g., Brown \& Wilderson, 2010; Carter Narendorf et al., 2018; Chambers et al., 2017, 2018, 2020; Chisholm-Straker et al., 2019; Choy-Brown et al., 2020; Crosby et al., 2018; Gibbs et al., 2015; Haner \& Pepler, 2017; Mitchell et al., 2016; Ruff \& Harrison, 2020; Thulien et al., 2019; Tyler et al., 2012);

- in indicating LGBT as a particularly vulnerable group (e.g., Axe et al., 2020; Elbedour et al., 2020; Robertson, 2013; Snyder et al., 2016; Stott, 2013);

- as considerations for future study (e.g., Aparicio et al., 2019);

- to note gaps in knowledge or attention and the need for additional resources or training (e.g., Bruce, 2016; Harmon-Darrow et al., 2020; Kaasbøll et al., 2019; Shpiegel \& Simmel, 2016; Stanley et al., 2015; Vacca \& Kramer-Vida, 2012); or,

- merely to explain that because the sample size of transgender youth was too small to be considered relevant, these participants were either excluded or rolled into other categories (e.g., Chisholm-Straker et al., 2019).

\section{International Journal of Child, Youth and Family Studies}

The International Journal of Child, Youth and Family Studies contained 20 relevant articles, including eight that focused on LGBTQ/queer topics, and four that focused on gender diversity and trans topics (Clark, 2017; Jack, 2020; Lee, 2019; Walker, 2014). The topics and foci within these journal articles included:

- social justice and responding to structural violence (Ajandi, 2011; de Finney et al., 2011; Lee, 2019; Richardson \& Reynolds, 2012; Saraceno, 2012);

- supportive resources for LGBTQ youth (Craig et al., 2014; Wolowic et al., 2018);

- gender as an important considersation for CYC practice and research (Hodgins, 2014; Kassis et al., 2015);

- how gender diversity is talked about and understood (Jack, 2020; Walker, 2014);

- practice issues and considerations with LGBTQ and gender-diverse youth (Cameron et al, 2017; Clark, 2017; Saewyc et al, 2014); and

- expanding current understandings of practice and theory within CYC (Artz et al., 2010; de Finney et al., 2012; Newbury, 2012; Skott-Myhre, 2012; Vachon, 2020; Yoon, 2012). 
International Journal of Child, Youth and Family Studies (2021) 12(3/4): 23-54

\section{Child and Youth Services}

Child and Youth Services contained eight relevant articles, including four that focused on queer and LGBTQ topics, and one that focused on transgender topics (Wagaman et al., 2019). These articles concerned themselves with:

- how challenging practice issues are talked about and understood (Ecker, 2016; Loiselle et al., 2012; Wagaman et al., 2019); and

- participatory and empowerment-based approaches for supporting youth (Capous-Desyllas \& Mountz, 2019; Gharabaghi \& Anderson-Nathe, 2018; Mayo, 2015; Stauss et al., 2016; Wagaman, 2015).

\section{CYC-Online}

CYC-Online contained three relevant articles. Two were related to LGBTQ and queer issues generally and one focused on a specific individual's personal experience with transitioning (SkottMyhre \& Wagner, 2014). The topics examined were the expansive possibility of transformation (Skott-Myher \& Wagner, 2014); the education of practitioners who may not be familiar with queer or transgender experiences (Fox, 2015); and the role of the practitioner in supporting queer and trans young people (Taylor, 2020).

\section{Relational Child and Youth Care Practice}

Relational Child and Youth Care Practice contained three relevant articles. Laidlaw (2010) discussed questioning and considering traditional gender roles and stereotypes for gendered expectations for children; Lebuis (2018) focused on utilizing humour to alleviate the stress of the coming out process for queer young people with regard to both sexual and gender identity; and Graham et al. (2018) discussed the experiences of racialized, trans, queer, and minoritized young people, and explored the transformative power of creating art with young people through excerpts from interviews with two youth participants in an audio-drama project called Transitioning Home.

\section{Child and Youth Care Forum}

This journal is mentioned here because it concerns itself directly with CYC. Unfortunately, despite this, in the 10-year period of interest, it did not include any articles that fell within the parameters for inclusion as relevant. Using the search strategy for this review, no articles were located that focused on LGBTQ or queer topics, or on T2SNB identities.

\section{Themes}

Amongst the articles reviewed, several key themes were identified, including gender and sexual diversity as a risk factor, education, and youth voice and participation, each of which is discussed in detail in the following sections. 
International Journal of Child, Youth and Family Studies (2021) 12(3/4): 23-54

\section{Gender and Sexual Diversity as a Risk Factor}

Many of the articles located for this review that broadly referenced LGBTQ populations or transgender participants focused on homelessness, sex work, addiction and substance use, experiences of violence, and youth suicide, emphasizing a link between gender and sexual diversity and "risk" for what is often seen as problematic behaviours, dangerous living conditions, and contexts in need of adult or system intervention.

As de Finney et al. (2011) stated, while all children are considered equal, "some children are more equal than others" (p. 364); they showed that there continues to be systemic minoritization of certain groups of children and youth, which is particularly evident in the overrepresentation of Indigenous, LGBTQ, and racialized children and youth within contexts of care such as residential care and the child welfare system. These authors called attention to the ways in which Indigenous, racialized, and queer and trans children and youth are theorized and understood as being in "need" of professional intervention in their lives (p. 367). Arguing that many services and care systems are entangled with normativity, the authors called for CYCPs to think deeply and critically about the ways in which we construct our care, enact our practices, and gather the information we use to inform our interventions. Without this critical approach, the authors argued, we risk conceptualizing care "as the rehabilitation of minoritized children and youth into unquestioned norms" (p. 368).

Wagaman (2015) discussed the challenges of the risk-resilience dichotomy, noting that a riskbased approached establishes a standard or expectation that young people are held to by practitioners and adults in their lives - a standard that values only those coping strategies deemed "positive", and labels resistance and ways of surviving that are outside of the norm of acceptable behaviours as "risk". This can, unintentionally, actually increase the hazards faced by LGBTQ young people by diverting attention away from systemic and contextual change towards individual behaviour management, thus reinforcing stigma and inequities (Wagaman, 2015). To challenge the risk- resilience dichotomy, Wagaman (2015) explored empowerment as a contrast to resilience, and recommended supporting young people to situate their experiences within social and historical contexts in order to help all involved (youth and workers) to deal directly with issues of oppression.

As Wagaman (2015) pointed out, while services targeted at supporting queer and trans young people have typically been risk-focused and prevention-oriented, we must consider the message underlying a risk framework: "Risk is often translated into a status characteristic of the young person rather than a characteristic that describes that person's experiences or context" (Russel, 2005 , p. 8, in Wagaman, 2015, p. 126). Wagaman also showed that this risk frame can and does contribute to the stigmatization and marginalization of young people. Ecker (2016) found that much of the research focused on the deficits and hardships facing homeless queer youth, but little research attended to the resiliency and strengths of these populations. Similarly, Gharabaghi and Anderson-Nathe (2018) noted that they have found that, "Quite a lot of research is unfolding with 
respect to young people focused on specific, often one-dimensional identity markers... Very often, such research seeks to highlight the damaged context of life that unfolds within these groups of young people" (p. 97). These authors argued that research frequently tends to start from a deficit orientation and a focus on the risk and damage within a particular group or population of young people. As an example, they noted that queer youth are uniformly seen as "at risk", with the result that research has focused on how to mitigate this risk. Gharabaghi and Anderson-Nathe (2018) further argued that "the historical record in the human services demonstrates clearly how research focused on interventions presupposes this damage narrative in which we can identify Us as experts and Them as victims" (p. 99). Ecker (2016) emphasized that it is important to understand what queer youth feel are their own strengths, beyond mere survival. While the levels of victimization and rates of violence that trans people experience are well-documented (e.g., Veale et al., 2015), and queer youth are disproportionately represented among the homeless population in both the United States and Canada (Ecker, 2016), research that moves beyond risk is direly needed. As Gharabaghi \& Anderson-Nathe (2018) concluded, "At the very least, we can say with confidence that queer youth are not victims of queerness; they face exclusion, judgement, and a firm designation as other" (p. 99).

In the same vein, Capous-Desyllas and Mountz (2019) showed that the majority of research about LGBTQ young people is centred in a risk framework with little to no attention given to youths' connections to each other and themselves. These authors built on previous findings that LGBTQ youth are not only overrepresented in the foster care system, but are also among the most poorly treated youth within it. Further, in keeping with her earlier research Wagaman, now with colleagues (2019), noted that until recently, research regarding trans young people has focused primarily on risk and victimization.

Lee (2019) tackled the complex topic of "how the Canadian immigration regime socially organizes the everyday lives of queer and trans migrants with precarious status" (p. 70), examining how participants navigated visa and permit eligibility criteria, crossed borders to enter Canada, and shifted between precarious statuses. While exploring the ways in which "heteronormative processes inform the Canadian immigration regime's production of precarity" (p. 76), Lee identified the particular ways in which queer and trans migrants experience structural violence. Lee's study focused on the institution of immigration in Canada, approaching the topic using institutional ethnography. While the focus on the creation and enactment of violence is articulated as institutional and structural, the theme remains that sexual or gender diversity puts one at risk for experiencing violence.

\section{Education}

A number of the articles reviewed spoke to the need for practitioner education, education for young people, and education in the community about queer and trans identities, needs, and issues. Among these, Ecker (2016) noted that it is important for both practitioners and researchers to be aware of their own knowledge of queer culture, including learning appropriate language and 
cultural terms; although some articles within CYC publications did briefly define such terms, few went so far as to discuss queer and trans identities and experiences in detail.

Clark (2017) cautioned practitioners that issues that arise in CYC practice with trans youth and their families can be complex and ethically challenging, and discussed how four ethical approaches (bioethics, rights-based ethics, relational ethics, and justice-doing) may be applied to practice situations involving trans youth and their families. Clark outlined the important role CYC workers can play in ensuring access to needed services as well providing direct support, information, and advocacy for trans youth and their families; and also encouraged critical thinking in practice with trans youth and their families. Further, Clark suggested that in order to practise ethically with trans young people and their families, practitioners must be aware of their own beliefs and biases, and must provide accurate, appropriate information and education. Similarly to Ecker (2016), Clark (2017) emphasized a need for education even though it is unclear where practitioners are to access this information and where this training is available, particularly for CYC workers.

Speaking to the experience of youth, Wolowic et al. (2018) explored the ways in which LGBTQ young people learn about and gain access to activities and supports within their community contexts that are supportive and inclusive of LGBTQ identities, and specifically investigated the ways in which LGBTQ people find and indicate safe spaces, inclusive services, and welcoming support or recreational environments. These authors found that clear, complete, and easily accessible information can support LGBTQ youth to take steps towards judging the relevancy and suitability of resources in their area, with many young people preferring online spaces as a safe and anonymous way to explore resources, rehearse new identities, and learn about others' experiences and identities. Taylor's (2020) research further built on the idea of creating safe services and support contexts, calling for practitioners to move beyond rainbow flags towards providing personal connections and support, and suggesting that the "out self" in practice can be a tool to support young people not only to access resources and supports in their communities including help from trusted individuals, particularly trusted adults — but also as a means of "vicarious resilience" (p. 23).

There was a noticeable gap in the articles reviewed regarding online spaces as educational resources and sites of connection, learning, and community. Through my previous research, which explored how Tumblr served as a site of language creation, exploration, and education for genderdiverse young people (Walker, 2017), I saw how online spaces are often a site of education and exploration for both youth and their caregivers. However, while Wolowic et al. (2018) identified the preference for online spaces, very few of the articles reviewed mentioned online spaces as sites of education and information-sharing for youth or their caregivers. The need remains for more research and practice information regarding young people's engagement with online spaces and the potential for online sites of service and support, particularly for young queer and trans people.

Several of the reviewed articles spoke to the importance of gay-straight alliances (GSAs; also known as gender-sexuality alliances) as spaces of learning and education within schools, and 
about the importance of bullying and suicide prevention programs for young people. Saewyc et al. (2014) found that GSAs and specific antihomophobic bullying policies were important schoolbased interventions that help prevent antigay discrimination, suicidal ideation, and suicide attempts among LGB youth, as well as among heterosexual youth; however, this study did not focus on trans or gender-diverse students.

Mayo (2015) offered a brief history of the development of GSAs in American schools and emphasized the potential of GSAs to be important sites of learning and education for young people regarding sexual and gender diversity and social justice. While noting the importance of GSAs, Mayo also offered a critique of the power dynamics present in the approach to learning and teaching in these groups, which are often run by teachers for students within the school. Mayo suggests that embracing a less hierarchical approach, utilizing the idea of "third space" (Zeichner, 2010 in Mayo, 2015), can create new learning opportunities valuing the knowledge of both students and the adults leading the groups. This approach allows for transformative spaces of learning for youth that can support the expansion of students' knowledge and activism, and encourage reflection, helping to create spaces for long-term learning and activism for students and schools. Mayo suggested that those best suited to leading GSAs and creating these spaces of learning are not teachers but youth workers, who may be better equipped to support youth with these topics, address power differentials, and connect with youth in less hierarchal ways.

Besides GSAs, other programs aimed at educating young people about issues pertaining to them were mentioned in the literature. Stauss et al. (2016) explored the effectiveness of a youth diversity program by looking at the sustaining effects of a week-long diversity youth camp program offered in the United States entitled "Ourtown for Teens". While Stauss et al. found that the program achieved positive and sustaining impacts for the participants, including gaining leadership skills and "greater understanding of "the other"' (p. 23), the researchers also found that the approach of educating participants about and "exposing" them to "the other" could also arguably perpetuate harmful and exclusionary behaviour. Despite this potential for risk, Stauss et al. found that after participation in the Ourtown for Teens program, many of the respondents were better able to analyze their own value systems, were more comfortable with themselves, and were more comfortable with those different from themselves.

In addition to articles that discussed educational programs for youth within the field, Fox (2015) offered readers an introductory lesson on LGBTQ terminology and identities as a "way of helping children and young people develop understanding and respect for differences in the human family" (p. 8). The goal of the article was to:

give us [CYCPs] all enough information to increase our comfort level with others of different feeling and attractions than our own. This is particularly important for the most marginalized group who need others who will be prepared to be the friend a transgendered person needs. (Fox, 2015, p. 13) 
International Journal of Child, Youth and Family Studies (2021) 12(3/4): 23-54

While Fox (2015) intended this article as a tool for understanding diverse identities, she offered a definition of transgender that is at odds with the prevailing definition, usage, and understanding of transgender and trans identities. Fox stated:

A transgender female feels and is most comfortable dressing and acting as a man in her culture would be expected to feel and act. A transgender male is a boy or man who feels and is most comfortable dressing and acting as a woman in his culture would be expected to feel and act. (p. 13)

Fox, unfortunately, misses the mark with these descriptions, as not only are these definitions incorrect, but the meaning of transgender is about far more than being comfortable in how one dresses and acts. As well, in her article, she uses forms of the term transgender (i.e., "a transgender" and "transgendered") that have been identified as harmful and disrespectful by trans individuals and communities (Kapitan, 2017; Serano, n.d.; Trans Journalists Association, n.d.). While terminology and language are continually shifting, adapting, and being created to describe and define gender experiences and identities (Walker, 2017), when terminology is misused and incorrectly applied it becomes harmful and disrespectful. While Fox's definition of transgender and her use of the term is an exception in the articles located within the CYC literature reviewed for this paper, it is noteworthy that this article was published as an educational piece in CYCOnline in 2015, yet still misused transgender terminology. This is perhaps an indication of the work that CYC researchers, writers, and educators still have to do on presenting informed, appropriate, and accurate information about sexual and gender diversity to the field.

\section{Youth Voice and Participation}

A primary theme across the literature reviewed was an emphasis on the importance of youth participation and youth's voices being accurately represented in the research, writing, and programming for trans and queer youth. Some articles discussed the importance of empowermentbased work and youth participation in research; other studies took up these suggestions by engaging directly with youth and emphasizing youth's voices in their findings.

Craig et al. (2014) focused on youth perspectives and input in regard to the It Gets Better Project (IGBP; n.d.), soliciting input from LGBTQ youth about the strengths and limitations of this popular online video project that was started by gay writer and activist, Dan Savage, and his husband Terry Miller in 2010 and is ongoing today. This study provides an example of centring youth voices and experiences with projects and interventions aimed at supporting them. Craig et al. (2014) found that the young people involved in their study felt the project was "a good starting point to raise awareness, but should evolve into tangible strategies to make it better for youth already experiencing risk" (p. 251), and that the program needed to focus on "making it better" for all LGBTQ youth, especially those who are ethnically or socioeconomically diverse. The youth called for researchers and the broader LGBTQ community to "build on the awareness generated from the IGBP and to provide more concrete strategies to impact youth suicide" (p. 214). One of the salient findings articulated by the youth was that the focus of the IGBP on asking youth to wait 
out their high school years in the anticipation that things will then get better may be an important message of hope; however, young people need tangible and accessible help now.

In their article on transformation, Skott-Myhre and Wagner (2014) shared Wagner's personal story, told in her own words, of transitioning and "becoming". Skott-Myhre introduced the theme of transformation as a site of possibility, framing Wagner's personal story as an example of the importance of growth, change, and transformation that occurs throughout development for young people. Their article, a powerful personal narrative, demonstrates that sharing personal stories is itself an important tool for learning and understanding diverse perspectives, but unfortunately provides only limited direct connections to practice applications with the CYC field.

Researchers have suggested that empowerment-based interventions and services are of particular benefit to individuals and communities that face systemic injustice and marginalization (Craig et al., 2014; Gameral et al., 2014; Gutiérrez et al., 2000; Matthews \& Salazar, 2012). When researchers engaged with young people who had been clients, or had been involved with the practice, care, and interventions offered by CYCPs, unique perspectives were revealed, leading to important and necessary insights. For example, Shelton (2015) explored young transgender people's experiences of homeless and of services for homeless youth, noting the pervasive binary understanding of gender, also known as cisgenderism, among services and supports. Drawing from experiences shared by the youth in the study, Shelton (2015) suggested the need to consider "unstably housed transgender and gender expansive young people as a distinct population with unique needs that differentiate them from their LGB counterparts" (p. 17), noting that transgender and gender-expansive young people who need services may find that the only services available are gender-based (e.g., gendered shelters).

Clark (2017) specifically focused on practice challenges and suggestions for practitioners working with transgender youth. Exploring different approaches to ethical dilemmas in practice with trans youth, Clark noted the flexibility and fluidity that comes with employing relational ethics and rights-based ethics that place importance on the youths' perspectives, voices, and participation. While the focus of the article is on the ethics of practice, Clark emphasized the importance of practitioners centring youth's perspectives in their own care and services.

Graham, Hightower, and Vachon (2018) offered an example of centring young people's perspectives on their own access to services and availability of appropriate and respectful care in the shelter system. Vachon interviewed Graham and Hightower about their own lived experiences and their involvement as characters in the Transitioning Home audio drama ${ }^{2}$. Moving between their personal stories and their connections to the characters portrayed in the podcast, both Graham and Hightower noted the need for respectful and safe shelter services for trans young people and how experiences of not being treating with dignity or respect may lead young people to choose to not access services at all and instead stay on the streets. Graham emphasized that when shelters

\footnotetext{
${ }^{2}$ https://transitioninghomepodcast.podbean.com/
} 
are designed with queer and trans young people in mind, they can become safer and more accessible for populations that have a demonstrated need for such services.

Wagaman et al. (2019) continued this line of discussion in their exploratory study documenting the ways in which transgender and gender-expansive youth engaged with community-based services. They emphasized the importance of utilizing the youths' own words to describe how the young people perceived and overcame their challenges. The authors highlighted the value of asking transgender and gender-expansive youth what they need, with their studying demonstrating, "a deepness in their [transgender and gender-expansive youths] insight and a clarity in what they were searching for to achieve" (p. 59) as well as their ability to live authentically.

Many of the articles reviewed here emphasized the importance of centring youth voices and experiences through research methods that focused on participation and youth engagement. Throughout these articles, methodologies that place importance on youth involvement and youth perspectives were identified. Capous-Desyllas and Mountz (2019) pointed out that photovoice, community-based, and participatory methodologies "tap into broader and more expansive and textured ways of knowing" (p. 299) and thus assist with empowerment. These researchers used photovoice to explore the experiences of LGBTQ youth in the foster care system, emphasizing the importance of building research capacity and "harnessing young people's power for creative selfexpression and collective representation" (p. 270). They noted that there was almost no research exploring the experiences of LGBTQ youth who were formerly in foster care, and that the photos and words in this study give voice to some of the distinct experiences that have not previously been a point of focus.

\section{Discussion}

While queer topics and identities received sparse attention within the CYC literature reviewed in this article, representation of trans identities and topics was scarcer still, and representation of Two-Spirit and nonbinary identities and topics was glaringly absent. This section highlights the continued gap in representation of T2SNB identities and topics within the currently available CYC literature, and discusses some of the challenges and debates that speak to the wider scope of research and writing on queer and trans identities and topics.

In their analysis of LGBTQ youth-serving organizations across numerous communities and within many schools in the United States, Allen et al. (2012) found that only half of the organizations they reviewed reported working with transgender young people. We cannot assume that a program ostensibly designed for LGBTQ young people is prepared for, or even accessible to, transgender young people (Wagaman et al., 2019). In Ecker's (2016) critical literature review on queer youth homelessness, he noted that the data on transgender individuals were masked or missing in many of the quantitative studies that compared the experiences of heterosexual and queer youth: such data were removed from the analysis, combined with data for other queer youth, or not included in the data collection in the first place. These findings mirror a similar pattern in 
the literature reviewed for this current paper. Wagaman et al. (2019) found that young people talked about their gender identities as being central to their interactions with the world and their sense of themselves, but this literature review has revealed that research specifically addressing gender identity within CYC is scarce.

In one of the few articles that I was able to locate that specifically focused on gender, Jack (2020) tackled the topic of gender reveal parties $^{3}$, articulating the ways in which expectant parents "reify gender difference and perform 'good' parenthood" (p. 83). While Jack's article does not specifically focus on queer or trans identities, it is included in this review as an important voice in the discussion of gender within CYC because it identifies the complex discourses and sociocultural conditions that children, youth, and families are steeped in, even prior to birth, and shows how this centralizes biological sex as a determinant of gender, identity, behaviour, and value within the family unit. Gender reveal parties are a growing trend, and are prominently featured on curated social media accounts where expectant parents share photos or videos of these events. Jack argued that these parties are not without harm and risk, despite being portrayed as "harmless fun": some of the videos Jack reviewed included scenes such as parents being visibly upset by the revealed sex, siblings crying, and property being damaged by fire through various means of creating coloured smoke. Most importantly, Jack draws attention to the ways in which these parties emphasize and solidify not only a limited binary expectation of gender but the "amount of power some give to genitals in dictating not only the kind of life they expect a child to have, but even what kind of relationship a parent of a particular sex can have with that child" (p. 89). Jack (2020) spoke to the important ways in which the existence and possibility of T2SNB individuals is ignored and erased within dominant parenting expectations, social media, and representation within North American and other Western contexts. What does it mean for CYCPs and researchers to contend with this lack of presence of queer and T2SNB identities in the media and in the resources within our own literature - the resources that are available to us and to the youth, families, and communities that we serve? In what ways can CYCPs take action to support the visibility, acceptance, and dignity of T2SNB individuals, families, and communities?

Taylor (2020) spoke of the "out self" as an important relational tool in CYC and articulated that "unlike other identity markers and characteristics, GSD [gender and sexual diversity] status may not always be quite as obvious until it is personally articulated by a given individual" (p. 24). CYCPs are "often taught to be mindful of boundaries and cautiously avoid any self-disclosure that could unintentionally lead to enmeshment" (p. 25); however, disclosure about sexual and gender identity for practitioners may be an important support to queer and T2SNB youth and offer representation and visibility to queer and T2SNB practitioners. In my own professional experience

\footnotetext{
${ }^{3}$ Jack noted that the term "gender reveal party" is a misnomer: these parties reveal the sex of the fetus as determined through identification of gendered genitals or chromosomes, not the gender (i.e., social role and identity) that the fetus will eventually assume. This is, at best, a guess by a healthcare provider, given that sex and gender are distinct categories that exist in "mutually informed and complex relationship with one another" (Fausto-Sterling, 2013 in Jack, 2020, p. 84).
} 
as a CYCP, it is becoming a common practice in many community groups, organizations, and some $\mathrm{CYC}$ classrooms to offer and inquire about pronouns when making introductions. However, as Taylor (2020) pointed out, this well-intentioned practice may also be potentially damaging as it can cause feelings of uncomfortable visibility. While the practice urges individuals to challenge their assumptions about how we recognize appearance and assume pronouns and gender, there are considerations in how and when we engage in the process and how we might open up other opportunities for individuals to share pronouns with their practitioners, instructors, or peers.

Beyond the reviewed CYC literature, Shelley (2008) noted that "repudiation of trans subjectivity ... lies at the heart of sectors of the 'helping' professions that seek to 'assist' trans people, usually with the aim of making them disappear into "normativity"” (p. 4). Shelley (2008) explored the critique that mental health supports aimed at "managing 'gender disorders" (p. 4) are inherently conflictual for trans people. Pervasive cisgenderism erases T2SNB people by structuring services in ways that become at least unwelcoming and at worst harmful (Shelton, 2015). Misgendering and pathologizing are two forms of cisgenderism explored within the literature in fields that are allied to CYC (Shelton, 2015). Shelton defines misgendering as "the inaccurate use of gendered language" to describe individuals, and pathologizing as "the labeling and treatment of people's self-designated genders as disordered" (2015, p. 11). Both misgendering and pathologizing contribute to the erasure of transgender people within current social contexts shaped by cisgenderism (Shelton, 2015).

De Finney et al. (2011) suggested that, "We need to ask critical questions about how we conceptualize the entangled relationship between normativity and service provision" (p. 368). When care is provided uncritically, without questioning what the needs of the young people and families with whom we work really are, we risk "rehabilitat[ing] minoritized children and youth into unquestioned norms" (de Finney et al., 2011, p. 368). Nevertheless, critical approaches to providing care are subverted by practice recommendations and policies that ignore real-world complexities (Gharabaghi \& Anderson-Nathe, 2017). As de Finney et al. (2011) pointed out, notions of relating to diversity are inadequately taken up within helping fields, such as CYC, as "cultural competence", a phrase suggesting that diversity and culture can be figured out, ignoring complex histories and intersections of multiple identities and subjectivities within communities. This idea of becoming "competent" in a culture or identity that is not your own suggests that a practitioner can arrive at a point of having learned enough about a community or identity that is different from their own experience to adequately understand it. This model of "competency" arguably presents cultures and identities as something that can be figured out and taught as an end product to new practitioners, instead of educating and supporting CYCPs to continually practise with approaches that place importance on working across difference, diversity, and complexity while centring dignity and respectful engagement.

Nevertheless, as Gharabaghi and Anderson-Nathe (2017) noted, when youth are identified by services or practitioners as "complex", they are often positioned as not fitting into available services: complexity is seen as a problem with the youth and not with the limitations of the services 
or models of practice available. With this in mind, Gharabaghi and Anderson Nathe (2017) suggested that the current discourse about the "complex young person" needs to shift its focus away from othering young people and towards describing (and acknowledging) the incapacities of services, institutions, and policies that are meant to work with young people in order to structure systems in ways that are more inclusive, thus offering new ways to exist and work "within difference, within multiple normative contexts and multiple intersections of identity and performance" (p. 2). Without asking critical questions about the aims of care and support work and without taking into account the true complexities of diverse subjectivities, practitioners will continue to perpetuate experiences of systemic violence, revictimization, and violence within systems of support and "care". This raises questions about what happens when "care" is harmful. As Vachon (2020) told us, there is remarkably little theory and writing that is directly about care in CYC: "While the word 'care' is everywhere in our publications, the actual deep thinking theorizing, conceptualizing, and grappling — is minimal" (p. 68).

Transgender and gender-diverse people continue to experience abuse and marginalization at the hands of those in positions of authority in systems of "care" (Browne et al., 2011; Shipherd \& Sloan, 2019). Throughout the current academic literature (e.g., Namaste, 2000; Shelley, 2008; Spade, 2015), and in community knowledge (Browne et al., 2011; Robles \& Edmiston, 2017), an overwheleming theme is that systems of care and support have historically been unsafe for trans people to access (Applegarth \& Nuttall, 2016) and continually create barriers to needed care: wideranging improvements are needed across helping fields to foster supportive and accessible services for trans people (Benaway, 2018; Shipherd \& Sloan, 2019). The question remains: In what ways are we as a field ensuring that our CYC practices are safe for queer and T2SNB young people?

Despite the many changes and (arguably) improvements in trans visibility and representation in media and pop culture, trans people continue to face transphobia and violence in systems of care (Benaway, 2018; Namaste, 2000; Shelley, 2008; Shipherd \& Sloan, 2019; Spade, 2015). When systems of support become systems of continued violence, queer and trans people are limited to the resources available within their own communities, face barriers to services and justice, and risk not receiving critical medical care during emergencies. Retraumatization and continuing repudiation (Shelley, 2008) are typical experiences of trans people even within systems of "support". As de Finney et al. (2011) showed, we can find similar patterns with systems of care that CYCPs find themselves aligned with, working for, and interacting with.

What is mostly absent in the CYC literature, as well as the other literature reviewed here, are suggestions for how to practise with queer and T2SNB young people and an examination of what care means for them. While some articles do take this up (e.g., Clark, 2017; Lee, 2019; Taylor, 2020), articles that directly inform or suggest practice approaches for working with T2SNB, and queer young people are uncommon. Articles focused on risk, experiences of violence, or critical theory of practice are far more prevalent than articles that explore what we as CYCPs can actually do differently. While both of these areas are inarguably crucial to our understanding of the work, practice-focused research is needed to support CYCPs integrate different ways of "knowing" and 
International Journal of Child, Youth and Family Studies (2021) 12(3/4): 23-54

"being", as well as "doing", into their CYC praxis (White, 2007) with queer and T2SNB young people.

Loiselle et al. (2012) challenged the "frequently voiced concern in CYC that critical theory and analysis are not useful for or relevant to frontline practice with young people, families, and communities" (p. 200), and found that this resistance within the field is not only deeply problematic but reinforces and reproduces "a false dichotomy between those who work with and those who think about children, youth, and families, as if working with and thinking about were mutually exclusive acts" (p. 200). Extending this challenging of dichotomies, Gharabaghi and Anderson-Nathe (2018) argued that the human services and CYC contexts perpetuate a divide between "us" as practitioner experts and "them" as victims. This can be extended further into considering the ways in which current CYC discourse presents those who are working with queer and trans young people and those who are queer or trans as mutually exclusive. By examining these discourses, contexts of practice, and embedded dichotomies and narratives, we reveal the ways in which we as a CYC field are erasing the presence of queer and trans identities and topics. As Vachon (2020) stated, "Acts of care take place within social and political contexts"; therefore, examining how these acts of care are performed reveals a lot about the context in which this care is embedded (p. 70).

\section{Conclusion}

As de Finney et al. (2011) stated, "Critically examining the work to which so many of us dedicate ourselves can be uncomfortable" (p. 377). These authors also pointed out that addressing power requires us to commit to a complex analysis and come to terms with multiple ways of knowing, despite "contradictions and messiness" (p. 377). Although there is a well-documented need for services and supports, intervention development for queer and trans young people is seriously lacking (Saewyc, 2011; Wagaman, 2015). Clark (2017) emphasized that, "It is our individual actions that can determine whether rights are upheld or violated, whether trans youth are supported or oppressed, and whether or not society becomes more just" (p. 91). Clark also stated that trans youth "have long been served by the child and youth care (CYC) profession" (p. 75); however, as this literature review has found, the representation of queer and trans identities, theories, and topics is scarce within CYC literature and research at this time. Queer and trans youth are unique populations that require specialized services to address their unique needs, implemented by "sensitive and knowledgeable staff" (Ecker, 2016, p. 325). Few articles in CYC address these topics, so it is time that we begin to critically examine the work that we are dedicating ourselves to and reflect on how and where we might make space for voices, writing, and research that take us beyond cis-heteronormative perspectives.

Loiselle et al. (2012) told us that "Thinking and embodying and doing CYC practice by interrogating structural inequities and affirming the survivance and presencing of communities and ecologies can be incredibly difficult, but not doing this is not an option" (p. 201). Vachon (2020) 
called for CYCPs to think of a queer CYC imagination as "one that recognizes, perhaps even celebrates desire, sex, identity, theory, and politics, and to wonder, together, what this might mean — what does queering CYC do?" (p. 64). As Lee (2019) noted, within the current global context, the human rights of queer and trans people continue to be debated and contested. If CYC is truly to be framed "as a site for radical theorizing, advocacy, and social change" (de Finney et al., 2011, p. 362), we must ask ourselves how we can make space for queer and trans identities and topics within our field, in order to work towards social change that shifts the field and challenges a cisheteronormative CYC system. 
International Journal of Child, Youth and Family Studies (2021) 12(3/4): 23-54

\section{References}

Ajandi, J. (2011). "Single mothers by choice": Disrupting dominant discourses of the family through social justice alternatives. International Journal of Child, Youth and Family Studies, 2(3/4), 410-431. doi:10.18357/ijcyfs23/420117757

Alessi, E. J., \& Martin, J. I. (2017). Intersection of trauma and identity. In K. L. Eckstrand \& J. Potter (Eds.), Trauma, resilience, and health promotion in LGBT patients: What every healthcare provider should know (pp. 3-14). Springer International Publishing. doi:10.1007/978-3-319-54509-7 1

Allen, K. D., Hammack, P.L., \& Himes, H. L. (2012). Analysis of LGBTQ youth communitybased programs in the United States. Journal of Homosexuality, 59, 1289-1306. $\underline{\text { doi: } 10.1080 / 00918369.2012 .720529}$

Aparicio, E. M., Kachingwe, O. N., Phillips, D. R., Fleishman, J., Novick, J., Okimoto, T., Kaleipumehana Cabral, M., Ka'opua, L. S., Childers, C., Espero, J., \& Anderson, K. (2019). Holistic, trauma-informed adolescent pregnancy prevention and sexual health promotion for female youth experiencing homelessness: Initial outcomes of Wahine Talk. Children and Youth Services Review, 107, Article 104509. doi:10.1016/j.childyouth.2019.104509

Applegarth, G., \& Nuttall, J. (2016). The lived experience of transgender people of talking therapies. International Journal of Transgenderism, 17(2), 66-72. doi:10.1080/15532739.2016.1149540

Artz, S., Nicholson, D., Halsall, E., \& Larke, S. (2010). Meaningful intervention with children and youth: A reflection on ten years of inquiry. International Journal of Child, Youth and Family Studies, 1(2), 118-133. doi:10.18357/ijcyfs122010671

Atteberry-Ash, B., Kattari, S. K., Speer, S. R., Guz, S., \& Kattari, L. (2019). School safety experiences of high school youth across sexual orientation and gender identity. Children and Youth Services Review, 104, Article 104403. doi:10.1016/j.childyouth.2019.104403

Axe, J., Childs, E., \& Manion, K. (2020). In search of employment: Tackling youth homelessness and unemployment. Children and Youth Services Review, 113, Article 104704. doi:10.1016/j.childyouth.2019.104704

Barth, R. P., \& Olsen, A. N. (2020). Are children oppressed? The timely importance of answering this question. Children and Youth Services Review, 110, Article 104780. doi:10.1016/j.childyouth.2020.104780

Begun, S., Frey, C., Combs, K. M., \& Torrie, M. (2019). "I guess it would be a good shock": A qualitative examination of homeless youths' diverse pregnancy attitudes. Children and Youth Services Review, 99, 87-96. doi:10.1016/j.childyouth.2019.01.029 
International Journal of Child, Youth and Family Studies (2021) 12(3/4): 23-54

Benaway, G. (2018, July 18). When it comes to health care, transphobia persists. The Globe and Mail. https:/www.theglobeandmail.com/opinion/article-when-it-comes-to-health-caretransphobia-persists/

Brown, S., \& Wilderson, D. (2010). Homelessness prevention for former foster youth: Utilization of transitional housing programs. Children and Youth Services Review, 32(10), 1464-1472. doi:10.1016/j.childyouth.2010.07.002

Browne, K., Bakshi, L., \& Lim, J. (2011). 'It's something you just have to ignore': Understanding and addressing contemporary lesbian, gay, bisexual and trans safety beyond hate crime paradigms. Journal of Social Policy, 40(4), 739-756. doi:10.1017/S0047279411000250

Bruce, J. S. (2016). Sexual and reproductive health policies for foster youth in California: A qualitative study of child welfare professionals' experiences and perceptions of policies. Children and Youth Services Review, 61, 184-200. doi:10.1016/j.childyouth.2015.12.016

Cameron, A., Luft, T., Dmytro, D., Kubiliene, N., \& Chou, W. (2017). Adolescents negotiating romantic relationships in a culturally diverse, urban community. International Journal of Child, Youth and Family Studies, 8(1), 1-19. doi:10.18357/ijcyfs81201716739

Capous-Desyllas, M., \& Mountz, S. (2019). Using photovoice methodology to illuminate the experiences of LGBTQ former foster youth. Child \& Youth Services, 40(3), 267-307. doi:10.1080/0145935X.2019.1583099

Carter Narendorf, S., Bowen, E., Santa Maria, D., \& Thibaudeau, E. (2018). Risk and resilience among young adults experiencing homelessness: A typology for service planning. Children and Youth Services Review, 86, 157-165. doi:10.1016/j.childyouth.2018.01.034

Chambers, R. M., Crutchfield, R. M., Willis, T. Y., Cuza, H. A., Otero, A., \& Carmichael, H. (2017). Perspectives: Former foster youth refining the definition of placement moves. Children and Youth Services Review, 73, 392-397. doi:10.1016/j.childyouth.2017.01.010

Chambers, R. M., Crutchfield, R. M., Willis, T. Y., Cuza, H. A., Otero, A., Goddu Harper, S. G., \& Carmichael, H. (2018). "It's just not right to move a kid that many times:" A qualitative study of how foster care alumni perceive placement moves. Children and Youth Services Review, 86, 76-83. doi:10.1016/j.childyouth.2018.01.028

Chambers, R. M., Crutchfield, R. M., Willis, T. Y., Cuza, H. A., Otero, A., Goddu Harper, S. G., \& Carmichael, H. (2020). "Be supportive and understanding of the stress that youth are going through:" Foster care alumni recommendations for youth, caregivers and caseworkers on placement transitions. Children and Youth Services Review, 108, Article 104644. doi:10.1016/j.childyouth.2019.104644 
International Journal of Child, Youth and Family Studies (2021) 12(3/4): 23-54

Chiang, S.-Y., Fleming, T., Lucassen, M. F. G., Fouche, C., \& Fenaughty, J. (2018). From secrecy to discretion: The views of psychological therapists on supporting Chinese sexual and gender minority young people. Children and Youth Services Review, 93, 307-314. doi:10.1016/j.childyouth.2018.08.005

Chisolm-Straker, M., Sze, J., Einbond, J., White, J., \& Stoklosa, H. (2019). Screening for human trafficking among homeless young adults. Children and Youth Services Review, 98, 72-79. doi:10.1016/j.childyouth.2018.12.014

Choy-Brown, M., Hamovitch, E. K., Bornheimer, L. A., Acri, M. C., \& McKay, M. M. (2020). Getting to the table: Agency characteristics and evidence-based intervention adoption in children's mental health care. Children and Youth Services Review, 110, Article 104774. doi:10.1016/j.childyouth.2020.104774

Clark, B. A. (2017). Ethics in child and youth care practice with transgender youth. International Journal of Child, Youth and Family Studies, 8(1), 74-96. doi:10.18357/ijcyfs82201716754

Coolhart, D., \& Brown, M. T. (2017). The need for safe spaces: Exploring the experiences of homeless LGBTQ youth in shelters. Children and Youth Services Review, 82, 230-238. doi:10.1016/j.childyouth.2017.09.021

Côté, P.-B., \& Blais, M. (2019). Between resignation, resistance and recognition: A qualitative analysis of LGBTQ+ youth profiles of homelessness agencies utilization. Children and Youth Services Review, 100, 437-443.doi:10.1016/j.childyouth.2019.03.024

Craig, S. L., \& Austin, A. (2016). The AFFIRM open pilot feasibility study: A brief affirmative cognitive behavioral coping skills group intervention for sexual and gender minority youth. Children and Youth Services Review, 64, 136-144. doi:10.1016/j.childyouth.2016.02.022

Craig, S. L., \& Austin, A. (2017). Childhood and adolescence. In K. L. Eckstrand \& J. Potter (Eds.), Trauma, resilience, and health promotion in LGBT patients: What every healthcare provider should know (pp. 57-73). Springer International Publishing. doi:10.1007/978-3-319$\underline{54509-7 \_6}$

Craig, S. L., McInroy, L. B., Alaggia, R., \& McCready, L. T. (2014). "Like picking up a seed, but you haven't planted it": Queer youth analyze the It Gets Better Project. International Journal of Child, Youth and Family Studies, 5(1), 204-219. doi:10.18357/ijcyfs.craigs1.512014

Craig, S. L., Tucker, E. W., \& Wagner, E. F. (2008). Empowering lesbian, gay, bisexual, and transgender youth: Lessons learned from a safe schools summit. Journal of Gay and Lesbian Social Services, 20(3), 237-252. doi:10.1080/10538720802235310 
International Journal of Child, Youth and Family Studies (2021) 12(3/4): 23-54

Crosby, S. D., Hsu, H.-T., Jones, K., \& Rice, E. (2018). Factors that contribute to help-seeking among homeless, trauma-exposed youth: A social-ecological perspective. Children and Youth Services Review, 93, 126-134. doi:10.1016/j.childyouth.2018.07.015

de Finney, S., Little, J. N. C., Skott-Myhre, H., \& Gharabaghi, K. (2012). Conversations on conversing in child and youth care. International Journal of Child, Youth and Family Studies, 3(2-3), 128-145. doi:10.18357/ijcyfs32-3201210862

de Finney, S., Dean, M., Loiselle, E., \& Saraceno, J. (2011). All children are equal, but some are more equal than others: Minoritization, structural inequities, and social justice praxis in residential care. International Journal of Child, Youth and Family Studies, 2(3/4), 361-384. doi:10.18357/ijcyfs23/420117756

Ecker, J. (2016). Queer, young, and homeless: A review of the literature. Child \& Youth Services, 37(4), 325-361. doi:org/10.1080/0145935X.2016.1151781

Elbedour, S., Alqahtani, S., El Sheikh Rihan, I., Bawalsah, J. A., Booker-Ammah, B., \& Turner, J. F. (2020). Cyberbullying: Roles of school psychologists and school counselors in addressing a pervasive social justice issue. Children and Youth Services Review, 109, Article 104720. doi:10.1016/j.childyouth.2019.104720

Everett, B., MacFarlane, D. A., Reynolds, V. A., \& Anderson, H. D. (2013). Not on our backs: Supporting counsellors in navigating the ethics of multiple relationships within queer, TwoSpirit, and/or trans communities. Canadian Journal of Counselling and Psychotherapy, 47(1), 14-28. https://cjc-rcc.ucalgary.ca/article/view/60940

Fox, L. (2015). Exploring sexual diversity: Helping children and young people develop understanding and respect for differences in the human family. CYC-Online, January 2015(191), 8-17.

Gamarel, K. E., Walker, J. J., Rivera, L., \& Golub, S. A. (2014). Identity safety and relational health in youth spaces: A needs assessment with LGBTQ youth of color. Journal of LGBT Youth, 11(3), 289-315. doi:10.1080/19361653.2013.879464

Gharabaghi, K., \& Anderson-Nathe, B. (2017). Troubling the emergent pathology of complexity. Child \& Youth Services, 38(4), 269-271. doi:10.1080/0145935X.2017.1411236

Gharabaghi, K., \& Anderson-Nathe, B. (2018). In a world of "Us" and "Them": The case against intervention-focused research. Child \& Youth Services, 39(2-3), 97-100. doi:10.1080/0145935X.2018.1531510

Gibbs, D. A., Hardison Walters, J. L., Lutnick, A., Miller, S., \& Kluckman, M. (2015). Services to domestic minor victims of sex trafficking: Opportunities for engagement and support. Children and Youth Services Review, 54, 1-7. doi:10.1016/j.childyouth.2015.04.003 
International Journal of Child, Youth and Family Studies (2021) 12(3/4): 23-54

Goldberg, A. E., Frost, R. L., Miranda, L., \& Kahn, E. (2019). LGBTQ individuals' experiences with delays and disruptions in the foster and adoption process. Children and Youth Services Review, 106, Article 104466. doi:10.1016/j.childyouth.2019.104466

Goldberg, A. E., Tornello, S., Farr, R., Smith, J. Z., \& Miranda, L. (2020). Barriers to adoption and foster care and openness to child characteristics among transgender adults. Children and Youth Services Review, 109, Article 104699. doi:10.1016/j.childyouth.2019.104699

Graham, J., Hightower, J., \& Vachon, W. (2018). Transitioning from home, to home: Ethics, safety, and aesthetics in community art creation. Relational Child \& Youth Care, 30(3), 5160 .

Gutiérrez, L., Oh, H. J., \& Gillmore, M. R. (2000). Toward an understanding of (em)power(ment) for HIV/AIDS prevention with adolescent women. Sex Roles, 42(7-8), 581-611. doi:10.1023/A:1007047306063

Haner, D., \& Pepler, D. (2017). Adolescents show positive changes in distress and hope after single session, post-based, anonymous counselling at Kids Help Phone. Children and Youth Services Review, 82, 207-213. doi:10.1016/j.childyouth.2017.09.004

Harmon-Darrow, C., Burruss, K., \& Finigan-Carr, N. (2020). "We are kind of their parents": Child welfare workers' perspective on sexuality education for foster youth. Children and Youth Services Review, 108, Article 104565. doi:10.1016/j.childyouth.2019.104565

Hodgins, B. D. (2014). Playing with dolls: (Re)storying gendered caring pedagogies. International Journal of Child, Youth and Family Studies, 5(4.2), 782-807. doi:10.18357/ijcyfs.hodginsbd.5422014

Hounmenou, C., \& O'Grady, C. (2019). A review and critique of the U.S. responses to the commercial sexual exploitation of children. Children and Youth Services Review, 98, 188198. doi:10.1016/j.childyouth.2019.01.005

Hunt, S. (2016). An introduction to the health of two-spirit people: Historical, contemporary and emergent issues. National Collaborating Centre for Aboriginal Health.

It Gets Better Project. (n.d.) About our global movement. https://itgetsbetter.org/about/

Jack, A. (2020). The gender reveal party. International Journal of Child, Youth and Family Studies, 11(2), 82-93. doi:10.18357/ijcyfs112202019520

Jenkins, A. (2015). The T is not silent: New and selected poems. Purple Lioness Productions. Jones-Smith, E. (2016). Theories of counselling and psychotherapy: An integrative approach (2nd ed). Sage. 
International Journal of Child, Youth and Family Studies (2021) 12(3/4): 23-54

Kaasbøll, J., Lassemo, E., Paulsen, V., Melby, L., \& Osborg, S. O. (2019). Foster parents' needs, perceptions and satisfaction with foster parent training: A systematic literature review. Children and Youth Services Review, 101, 33-41. doi:10.1016/j.childyouth.2019.03.041

Kapitan, A. (2017, updated October 2020). The radical copyeditor's style guide for writing about transgender people. The Radical Copyeditor. https://radicalcopyeditor.com/2017/08/31/transgender-style-guide/

Kassis, W., Artz, S., Moldenhauer, S., Géczy, I., \& Rossiter, K. (2015). A dynamic and gender sensitive understanding of adolescents' personal and school resilience characteristics despite family violence: The predictive power of the family violence burden level. International Journal of Child, Youth and Family Studies, 6(3), 388-420. doi:10.18357/ijcyfs.63201513562

Laidlaw, L. (2010). Gender bender. Relational Child and Youth Care Practice, 23(3), 14-15.

Lebuis, P. (2018). Coming out laughing. Relational Child and Youth Care Practice, 31(2), 2625.

Lee, E. O. J. (2019). Responses to structural violence: The everyday ways in which queer and trans migrants with precarious status respond to and resist the Canadian immigration regime. International Journal of Child, Youth and Family Studies, 10(1), 70-94. doi:10.18357/ijcyfs101201918807

Lev, A. I. (2004). Transgender emergence: Therapeutic guidelines for working with gendervariant people and their families. The Haworth Clinical Practice Press. doi:10.4324/9780203047781

Loiselle, E., de Finney, S., Khanna, N., \& Corcoran, R. (2012). "We need to talk about it!": Doing CYC as politicized praxis. Child \& Youth Services, 33(3-4), 178-205. doi:10.1080/0145935X.2012.745778

Maccio, E. M., \& Ferguson, K. M. (2016). Services to LGBTQ runaway and homeless youth: Gaps and recommendations. Children and Youth Services Review, 63, 47-57. doi:10.1016/j.childyouth.2016.02.008

Matthews, C. H., \& Salazar, C. F. (2012). An integrative, empowerment model for helping lesbian, gay, and bisexual youth negotiate the coming-out process. Journal of LGBT Issues in Counseling, 6(2), 96-117. doi:10.1080/15538605.2012.678176

Mayo, J. B., Jr. (2015). Youth work in gay straight alliances: Curriculum, pedagogy, and activist development. Child \& Youth Services, 36(1), 79-93. doi:10.1080/0145935X.2015.1015887

Mayo, C. (2017). Queer and trans youth, relational subjectivity, and uncertain possibilities: Challenging research in complicated contexts. Educational Researcher, 46(9), 530-538. doi:10.3102/0013189X17738737 
International Journal of Child, Youth and Family Studies (2021) 12(3/4): 23-54

Mitchell, P. F., Kutin, J. J., Daley, K., Best, D., \& Bruun, A. J. (2016). Gender differences in psychosocial complexity for a cohort of adolescents attending youth-specific substance abuse services. Children and Youth Services Review, 68, 34-43.

doi:10.1016/j.childyouth.2016.06.016

Mizock, L., \& Lewis, T. (2008). Trauma in transgender populations: Risk, resilience, and clinical care. Journal of Emotional Abuse, 8(3), 335-354. doi:10.1080/10926790802262523

Mountz, S., \& Capous-Desyllas, M. (2020). Exploring the families of origin of LGBTQ former foster youth and their trajectories throughout care. Children and Youth Services Review, 109, Article 104622. doi:10.1016/j.childyouth.2019.104622

Namaste, V. (2000). Invisible lives: The erasure of transsexual and transgendered people. University of Chicago Press.

Newbury, J. (2012). The paradox of the individual. International Journal of Child, Youth and Family Studies, 3(4.1), 458-478. doi:10.18357/ijcyfs34.1201211545

Prock, K. A., \& Kennedy, A. C. (2017). Federally-funded transitional living programs and services for LGBTQ-identified homeless youth: A profile in unmet need. Children and Youth Services Review, 83, 17-24. doi:10.1016/j.childyouth.2017.10.023

Rew, L., Slesnick, N., Johnson, K., Aguilar, R., \& Cengiz, A. (2019). Positive attributes and life satisfaction in homeless youth. Children and Youth Services Review, 100, 1-8. doi:10.1016/j.childyouth.2019.02.021

Richardson, C. L., \& Reynolds, V. (2012). "Here we are, amazingly alive": Holding ourselves together with an ethic of social justice in community work. International Journal of Child, Youth and Family Studies, 3(1), 1-19. doi:10.18357/ijcyfs31201210471

Richards-Schuster, K., Juras, J., Young, S. R., \& Timmermans, R. J. (2013). What constitutes youth organizing? Exploring the role of conservative contexts in understanding practice. Children and Youth Services Review, 35(8), 1291-1296. doi:10.1016/j.childyouth.2013.04.017

Robertson, R. D. (2013). The invisibility of adolescent sexual development in foster care: Seriously addressing sexually transmitted infections and access to services. Children and Youth Services Review, 35(3), 493-504. doi:10.1016/j.childyouth.2012.12.009

Robles, R. J., \& Edmiston, E. K. (2017). Community responses to trauma. In K. L. Eckstrand \& J. Potter (Eds.), Trauma, resilience, and health promotion in LGBT patients: What every healthcare provider should know (pp. 231-243). Springer International Publishing. doi:10.1007/978-3-319-54509-7 19 
International Journal of Child, Youth and Family Studies (2021) 12(3/4): 23-54

Ruff, S. C., \& Harrison, K. (2020). “Ask me what I want”: Community-based participatory research to explore transition-age foster youth's use of support services. Children and Youth Services Review, 108, Article 104608. doi:10.1016/j.childyouth.2019.104608

Saewyc, E. M. (2011). Research on adolescent sexual orientation: Development, health disparitites, stigma, and resilience. Journal of Research on Adolescence, 21(1), 256-272. doi:10.1111/j.1532-7795.2010.00727.x

Saewyc, E., Konishi, C., Rose, H., \& Homma, Y. (2014). School-based strategies to reduce suicidal ideation, suicide attempts, and discrimination among sexual minority and heterosexual adolescents in western Canada. International Journal of Child, Youth and Family Studies, 5(1), 89-112. doi:10.18357/ijcyfs.saewyce.512014

Saraceno, J. (2012). Mapping whiteness and coloniality in the human service field: Possibilities for a praxis of social justice in child and youth care. International Journal of Child, Youth and Family Studies, 3(2-3), 248-271. doi:10.18357/ijcyfs32-3201210869

Scannapieco, M., Painter, K. R., \& Blau, G. (2018). A comparison of LGBTQ youth and heterosexual youth in the child welfare system: Mental health and substance abuse occurrence and outcomes. Children and Youth Services Review, 91, 39-46.

doi:10.1016/j.childyouth.2018.05.016

Seelman, K. L., Forge, N., Walls, N. E., \& Bridges, N. (2015). School engagement among LGBTQ high school students: The roles of safe adults and gay-straight alliance characteristics. Children and Youth Services Review, 57, 19-29. doi:10.1016/j.childyouth.2015.07.021

Serano, J. (n.d.). There is no perfect word: A transgender glossary of sorts. http://www.juliaserano.com/terminology.html

Shelley, C. A. (2008). Transpeople: Repudiation, trauma, and healing. Univeristy of Toronto Press.

Shelton, J. (2015). Transgender youth homelessness: Understanding programmatic barriers through the lens of cisgenderism. Children and Youth Services Review, 59, 10-18. doi:10.1016/j.childyouth.2015.10.006

Shipherd, J. C., \& Sloan, C. A. (2019). The therapy room and beyond: Necessary action when working with gender minority people. Cognitive and Behavioral Practice, 26(4), 589-591. doi:10.1016/j.cbpra.2019.07.011

Shpiegel, S., \& Simmel, C. (2016). Functional outcomes among sexual minority youth emancipating from the child welfare system. Children and Youth Services Review, 61, 101108. doi:10.1016/j.childyouth.2015.12.012 
International Journal of Child, Youth and Family Studies (2021) 12(3/4): 23-54

Skott-Myhre, H., \& Wagner, D. (2014). Becoming Dani. CYC-Online, January 2014(179), 3841. https://cyc-net.org/cyc-online/jan2014.pdf

Skott-Myhre, K. (2012). Nomadic youth care. International Journal of Child, Youth and Family Studies, 3(2-3), 300-315. doi:10.18357/ijcyfs32-3201210872

Snyder, S. M., Hartinger-Saunders, R., Brezina, T., Beck, E., Wright, E. R., Forge, N., \& Bride, B. E. (2016). Homeless youth, strain, and justice system involvement: An application of general strain theory. Children and Youth Services Review, 62, 90-96.

doi:10.1016/j.childyouth.2016.02.002

Spade, D. (2015). Normal life: Adminstrative violence, critical trans politics, and the limits of law. Duke University Press.

Stanley, N., Ellis, J., Farrelly, N., Hollinghurst, S., \& Downe, S. (2015). Preventing domestic abuse for children and young people: A review of school-based interventions. Children and Youth Services Review, 59, 120-131. doi:10.1016/j.childyouth.2015.10.018

Stauss, K., Koh, E., Coustaut, C., \& Ayers, B. (2016). Ourtown for teens: Long-term impact of a youth diversity program. Child \& Youth Services, 37(1), 23-48.

doi:10.1080/0145935X.2015.1052134

Stott, T. (2013). Transitioning youth: Policies and outcomes. Children and Youth Services Review, 35(2), 218-227. doi:10.1016/j.childyouth.2012.10.019

Taylor, G. (2020). Beyond rainbow flag stickers \& safe space signs: Exploring gender and sexual identity within the 'here and now' of child and youth care practice. CYC-Online, March 2020(253), 22-33. https://cyc-net.org/cyc-online/mar2020.pdf

Thulien, N. S., Gastaldo, D., McCay, E., \& Hwang, S. W. (2019). "I want to be able to show everyone that it is possible to go from being nothing in the world to being something": Identity as a determinant of social integration. Children and Youth Services Review, 96, 118126. doi:10.1016/j.childyouth.2018.11.005

Trans Journalists Association (n.d.). Style guide. https://transjournalists.org/style-guide/

Tyler, K. A., Akinyemi, S. L., \& Kort-Butler, L. A. (2012). Correlates of service utilization among homeless youth. Children and Youth Services Review, 34(7), 1344-1350.

doi:10.1016/j.childyouth.2012.03.010

Vacca, J. S., \& Kramer-Vida, L. (2012). Preventing the bullying of foster children in our schools. Children and Youth Services Review, 34(9), 1805-1809.

doi:10.1016/j.childyouth.2012.05.014 
International Journal of Child, Youth and Family Studies (2021) 12(3/4): 23-54

Vachon, W. (2020). Queering child and youth care. International Journal of Child, Youth and Family Studies, 11(2), 61-81. doi:10.18357/ijcyfs112202019519

Veale, J., Saewyc, E., Frohard-Dourlent, H., Dobson, S., Clark, B., \& the Canadian Trans Youth Health Survey Research Group (2015). Being safe, being me: Results of the Canadian trans youth health survey. Stigma and Resilience Among Vulnerable Youth Centre, School of Nursing, University of British Columbia. https:/www.saravyc.ubc.ca/2018/05/06/trans-youthhealth-survey/

Wagaman, M. A. (2015). Changing ourselves, changing the world: Assessing the value of participatory action research as an empowerment-based research and service approach with LGBTQ young people. Child \& Youth Services, 36(2), 124-149. doi:10.1080/0145935X.2014.1001064

Wagaman, M. A., Shelton, J., Carter, R., Stewart, K., \& Cavaliere, S. J. (2019). "I'm totally transariffic": Exploring how transgender and gender-expansive youth and young adults make sense of their challenges and successes. Child \& Youth Services, 40(1), 43-64. doi:10.1080/0145935X.2018.1551058

Wagaman, M. A., Watts, K. J., Lamneck, V., D’Souza, S. A., McInroy, L. B., Eaton, A. D., \& Craig, S. (2020). Managing stressors online and offline: LGBTQ+ youth in the Southern United States. Children and Youth Services Review, 110, Article 104799. doi:10.1016/j.childyouth.2020.104799

Walker, E. M. (2017). "I am something else. For now": Exploring youth conversations about gender online [Master's thesis, University of Victoria]. https://dspace.library.uvic.ca/handle/1828/8642

Walker, M. (2014). Gender and language: Examining the use of diagnostic language in the discussion of gender variance. International Journal of Child, Youth and Family Studies, 5(2), 332-345. doi:10.18357/ijcyfs.walkerm.522014

Wells, E. A., Asakura, K., Hoppe, M. J., Balsam, K. F., Morrison, D. M., \& Beadnell, B. (2013). Social services for sexual minority youth: Preferences for what, where, and how services are delivered. Children and Youth Services Review, 35(2), 312-320. doi:10.1016/j.childyouth.2012.11.011

Wernick, L. J., Dessel, A. B., Kulick, A., \& Graham, L. F. (2013). LGBTQQ youth creating change: Developing allies against bullying through performance and dialogue. Children and Youth Services Review, 35(9), 1576-1586. doi:10.1016/j.childyouth.2013.06.005

Wernick, L. J., Kulick, A., \& Inglehart, M. H. (2013). Factors predicting student intervention when witnessing anti-LGBTQ harassment: The influence of peers, teachers, and climate. Children and Youth Services Review, 35(2), 296-301. doi:10.1016/j.childyouth.2012.11.003 
International Journal of Child, Youth and Family Studies (2021) 12(3/4): 23-54

White, J. (2007). Knowing, doing and being in context: A praxis-oriented approach to child and youth care. Child \& Youth Care Forum, 36(5), 225-244. doi:10.1007/s10566-007-9043-1

White, J. (2015). An ethos for the times: Difference, imagination, and the unknown future in child and youth care. International Journal of Child, Youth and Family Studies, 6(4), 498515. doi:10.18357/ijcyfs. 64201514285

Wilson, B. D. M., \& Kastanis, A. A. (2015). Sexual and gender minority disproportionality and disparities in child welfare: A population-based study. Children and Youth Services Review, 58, 11-17. doi:10.1016/j.childyouth.2015.08.016

Wolowic, J. M., Sullivan, R., Valdez, C. A. B., Porta, C. M., \& Eisenberg, M. (2018). Come along with me: Linking LGBTQ youth to supportive resources. International Journal of Child, Youth and Family Studies, 9(3), 1-20. doi:10.18357/ijcyfs93201818274

Yoon, J.-S. (2012). Courageous conversations in child and youth care: Nothing lost in the telling. International Journal of Child, Youth and Family Studies, 3(2-3), 164-186.

doi:10.18357/ijcyfs32-3201210864 